\title{
Correlation Between Dysphagia and Malocclusion in Rett Syndrome A preliminary study
}

Serena Cocca, ${ }^{1}$ Massimo Viviano, ${ }^{2}$ Michele Loglisci, ${ }^{1}$ Stefano Parrini, ${ }^{3}$ Giovanni Monciatti, ${ }^{1}$ Ilaria I. Paganelli, ${ }^{1}$ Walter Livi, ${ }^{1}$ "Chiara Mezzedimi ${ }^{1}$

$$
\text { الترابط بين عسر البلع وسوء الإطباق في متلازمة ريت }
$$

سيرينا كوكا، ماسيمو فيفيانو، ميشيل لوجليسي، ستيفانو باريني، جيوفاني مونسياتي، إيلاريا إينوسنتي باغانيللي، والتر ليفي، كيارا ميزيديمي

ABSTRACT: Objectives: Rett syndrome (RS) is a severe neurological developmental disorder characterised by stereotypical hand movements, epileptic seizures, craniofacial dysmorphism and digestive dysfunction. This study aimed to examine the correlation between the severity of malocclusion and dysphagia in patients with RS. Methods: This preliminary study was conducted at the Ear, Nose \& Throat Clinic of the University Hospital of Siena, Siena, Italy, from January 2014 to December 2017. A total of 56 patients with RS were examined and grouped according to the severity of dysphagia (absent, mild, moderate or severe) and malocclusion $(<2 \mathrm{~mm}, 2-3 \mathrm{~mm}, 3-4 \mathrm{~mm}$ or $>4$ $\mathrm{mm})$. Results: All of the patients were female and the mean age was 11.3 years. Eight (14.3\%) patients had mild, 18 (32.1\%) had moderate and 30 (53.6\%) had severe dysphagia. Four (7.1\%) patients had $<2 \mathrm{~mm}$ occlusion, 10 (17.9\%) had 2-3 mm occlusion, 26 (46.4\%) had 3-4 mm occlusion and 16 (28.6\%) had >4 mm occlusion. Mild dysphagia was observed in $100 \%$ and $40 \%$ of patients with $<2$ and $2-3 \mathrm{~mm}$ malocclusion, respectively, while moderate dysphagia was present in $60 \%$ and $38.5 \%$ of patients with $2-3$ and $3-4 \mathrm{~mm}$ malocclusion, respectively. Severe dysphagia was observed in $28.6 \%$ and $87.5 \%$ of patients with $3-4$ and $>4 \mathrm{~mm}$ malocclusion, respectively. There was a significant correlation between dysphagia and malocclusion severity $(P<0.001)$. Conclusion: A higher degree of malocclusion was associated with more severe dysphagia among a cohort of patients with RS.

Keywords: X-Linked Mental Retardation; Rett Syndrome; Dysphagia; Malocclusion; Feeding and Eating Disorders of Childhood.

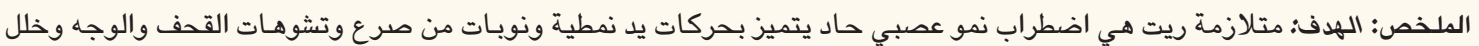

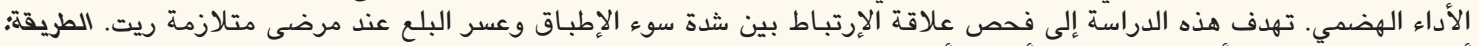

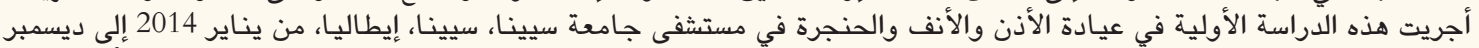

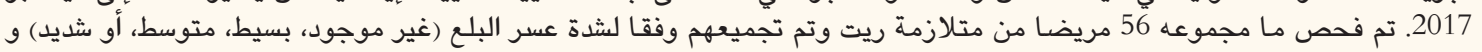

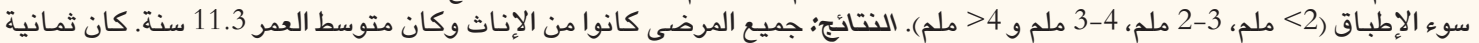

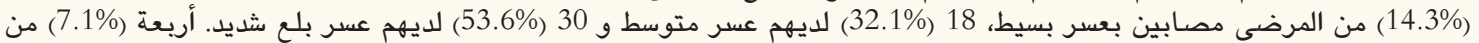

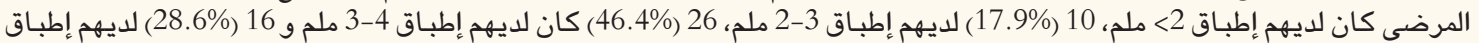

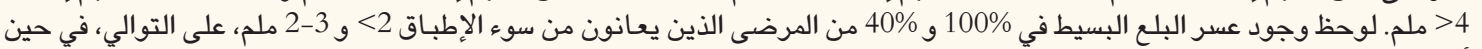

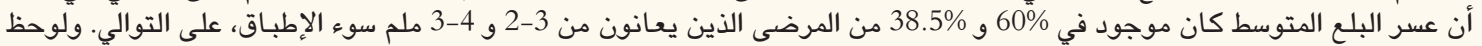

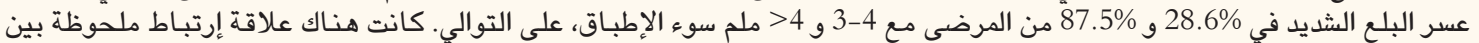

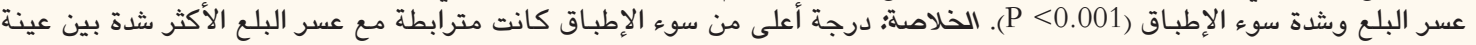
المرضى المصابين بمتلازمة رئرة الإطياق

الكلمات المفتاحية: التخلف العقلي المرتبط بـالجنس؛ متلازمة ريت؛ عسر البلع؛ سوء الإطباق؛ التغذية واضطراب الأكل عند الأطفال.

\section{AdvanCeS IN KNOWLedge}

The findings of this study indicate that a high degree of malocclusion is associated with more severe dysphagia in patients with Rett syndrome.

\section{Application to Patient Care}

Correcting malocclusion may improve the oral preparatory phase of swallowing, thereby enabling patients with feeding and eating disorders to have a natural diet. This reduces the risk of ab ingestis pneumonia and offers a recourse to percutaneous endoscopic gastrostomy, thus improving the patient's quality of life. 
$\mathrm{R}$ ETT SYNDROME (RS) IS A RARE NEUROLOGICAL disorder which occurs in approximately one in 10,000 live births and develops almost exclusively among females due to an X-linked dominant mutation. ${ }^{1,2}$ First described by Andreas Rett in 1966, RS is the second most common cause of mental retardation in females after Down's syndrome. ${ }^{1,3}$ Classical RS, the most common form, is characterised by a mutation in the methyl-CpG-binding protein 2 gene. ${ }^{4}$ The diagnosis is mostly based on clinical characteristics, clinical course and genetic/molecular testing. ${ }^{1,2}$ In addition, other atypical forms of RS may present with different symptoms and/or mutations. ${ }^{4,5}$

The disease is characterised by abnormal hand movements, epileptic seizures, craniofacial dysmorphism and digestive system problems. ${ }^{1}$ Affected patients appear to develop normally until two years of age, at which point they begin to manifest motor and speech disabilities. In addition, the syndrome can present with autism, ataxia and intermittent hypoventilation. ${ }^{1}$ The condition subsequently stabilises and patients can live to adulthood. Hagberg defined four stages of classical RS: (1) early-onset stagnation marked by delayed developmental milestones; (2) developmental regression with a loss of acquired skills/communication and signs of mental retardation; (3) apparent walking difficulties and slow neuromotor regression; and (4) late motor deterioration resulting in complete wheelchair dependency, weight loss and skeletal deformities. ${ }^{6}$

Patients with RS often have feeding and digestive problems aggravated by poor bolus preparation/propulsion, respiratory anomalies, ineffective tongue movements, incomplete chewing and head and neck dysmorphism (e.g. advancement of the maxilla, neuromuscular insufficiency and back deformities).$^{6-12}$ Dental anomalies are also common, such as open bite due to the absence of vertical overlap/contact between the anterior maxillary and mandibular teeth and malocclusion resulting from unfavourable growth patterns and incorrect mandibular positioning associated with exacerbated open-mouth breathing and tongue thrusting habits [Figure 1]. 7,13,14 Bruxism is also a typical feature, although it is not pathognomonic. The current study aimed to evaluate oral and dental characteristics in a series of patients with RS in order to determine a correlation between the severity of malocclusion and dysphagia.
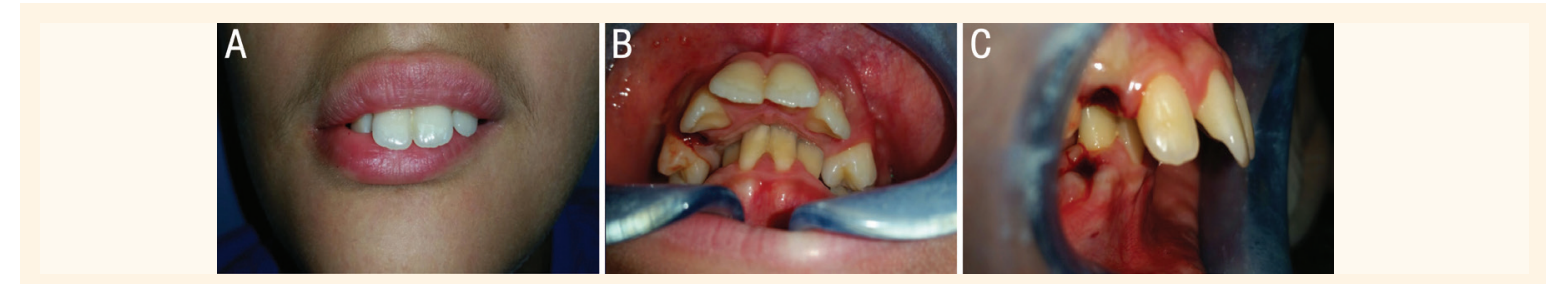

Figure 1: Photographs of a 14-year-old girl with Rett syndrome showing typical dental features of (A) maxillary advance-

ment and (B) maxillary protrusion, resulting in (C) misalignment of the maxillary and mandibular teeth (i.e. malocclusion).

This preliminary study was conducted at the Ear, Nose \& Throat (ENT) Clinic of the University Hospital of Siena, Siena, Italy, from January 2014 to December 2017. A total of 56 patients with classical RS admitted to the ENT Clinic were randomly enrolled in the study. Various clinical examinations were conducted during hospitalisation, including history-taking, body weight and height measurements as well as laryngological, ENT, speech and dental evaluations. Patients were also monitored during mealtimes and underwent evaluations by a speech therapist. In addition, detailed feeding histories were taken from parents/caregivers during interviews. The same speech therapist evaluated all of the patients so as to ensure reliable results. The perioral tissue, oral mucosa and tongue of each patient was assessed by a dentist.

As part of the laryngological evaluation, the patients underwent a partial fiberoptic endoscopic evaluation of the pharynx and larynx during and after the act of swallowing for the detection of uncontrolled bolus, piecemeal deglutition, premature loss of liquid, vallecular and pyriform sinus residue, aspiration and absence of cough reflex. However, due to poor patient compliance, only a partial endoscopic assessment of swallowing could be performed to establish the severity of dysphagia. The endoscopic evaluation was performed without anaesthesia while the patient was at rest after being fed 2-3 spoons of a semi-liquid bolus of water gel.

All patients were classified according to dysphagia severity. Mild dysphagia was defined as slight coughing while eating, oral leakage/drooling, no choking, no vocal fold alterations, good laryngeal sensitivity and minimal stagnation of secretions in the pyriform sinuses., ${ }^{7,13}$ Moderate dysphagia was indicated by delayed pharyngeal clearance of vallecular and pyriform sinus secretions, abundant coughing after eating, slow laryngeal sphincter function and a high risk of aspiration. Finally, severe dysphagia was defined as an absence of coughing, ineffective pharyngeal clearance, permanent post-swallow residue, premature loss of liquid or uncontrolled bolus, poor deglutitive airway protection and a very high risk of aspiration. ${ }^{7,13}$ Patients with normal swallowing were deemed not to have any dysphagia. 
Table 1: Oral and dental characteristics of patients with Rett syndrome admitted to the University Hospital of Siena, Siena, Italy $(\mathrm{N}=56)$

$\begin{array}{lc}\text { Characteristic } & \mathbf{n}(\%) \\ \text { Open bite } & 50(89.3) \\ \text { Open-mouth breathing } & 46(82.1) \\ \text { Drooling } & 52(92.9) \\ \text { Reduced lip continence } & 56(100) \\ \text { Bruxism } & 48(85.7) \\ \text { Involuntary tongue movements } & 46(82.1) \\ \text { Poor lateralisation of the tongue } & 52(92.9)\end{array}$

Table 2: Severity of malocclusion and dysphagia among patients with Rett syndrome admitted to the University Hospital of Siena, Siena, Italy $(\mathrm{N}=56)$

\begin{tabular}{lcccc}
$\begin{array}{l}\text { Dysphagia } \\
\text { severity }\end{array}$ & \multicolumn{4}{c}{ Malocclusion severity*, $\mathbf{n}(\%)$} \\
& $\begin{array}{l}<2 \mathrm{~mm} \\
(\mathbf{n}=4)\end{array}$ & $\begin{array}{c}\mathbf{2 - 3} \mathbf{~ m m} \\
(\mathbf{n}=10)\end{array}$ & $\begin{array}{c}3-4 \mathbf{m m} \\
(\mathbf{n}=\mathbf{2 6})\end{array}$ & $\begin{array}{c}>\mathbf{4} \mathbf{~ m m} \\
(\mathbf{n}=16)\end{array}$ \\
Mild & $4(100)$ & $4(40)$ & $0(0)$ & $0(0)$ \\
Moderate & $0(0)$ & $6(60)$ & $10(38.5)$ & $2(12.5)$ \\
Severe & $0(0)$ & $0(0)$ & $16(28.6)$ & $14(87.5)$
\end{tabular}

"Defined as the distance between the mesiobuccal cusp of the maxillary first molar and mesiobuccal groove of the mandibular first molar in the sagittal plane.

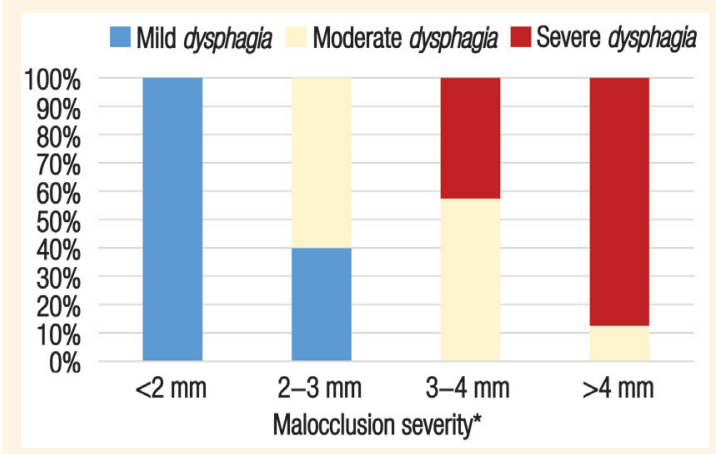

Figure 2: Severity of malocclusion and dysphagia among patients with Rett syndrome admitted to the University Hospital of Siena, Siena, Italy $(\mathrm{N}=56)$.

"Defined as the distance between the mesiobuccal cusp of the maxillary first molar and mesiobuccal groove of the mandibular first molar in the sagittal plane.

Occlusion was categorised using Angle's classification according to the relationship between the mesiobuccal cusp of the maxillary first molar and the mesiobuccal groove of the mandibular first molar. ${ }^{15}$ Class I was defined as the alignment of the mesiobuccal cusp of the maxillary first molar with the mesiobuccal groove of the mandibular first molar (i.e. neutral or normal occlusion). Class II was indicated in cases wherein the mesiobuccal groove of the lower first molar aligned posteriorly to the mesiobuccal cusp of the maxillary first molar (i.e. distocclusion). ${ }^{15}$ Depending on the position of the anterior teeth, patients with class II occlusion were subdivided into either division one (proclined upper incisors) or two (lingually inclined upper central incisors possibly overlapped by the upper later incisors). For class III occlusion, the mesiobuccal groove of the mandibular first molar aligned anteriorly to the mesiobuccal cusp of the maxillary first molar (i.e. mesiocclusion). ${ }^{15}$ Malocclusion severity was assessed in terms of the distance between the mesiobuccal cusp of the maxillary first molar and mesiobuccal groove of the mandibular first molar in the sagittal plane $(<2 \mathrm{~mm}$, 2-3 $\mathrm{mm}, 3-4 \mathrm{~mm}$ or $>4 \mathrm{~mm}$ ).

Data were analysed by linear regression using Graph Pad Software (GraphPad Software Inc., La Jolla, California, USA). A $P$ value of $<0.001$ was considered statistically significant. This study was approved by the local ethics committee of the Tuscany Region Area Vasta Sud Est (\#22.1.14). Both parents or legal guardians of each patient provided informed written consent for their participation in the study.

\section{Results}

All 56 patients were female. The mean age was 11.3 years (range: 8-17 years old) and the patients resided in the southern (59\%), central (22\%) and northern (19\%) regions of Italy. All cases showed an early arrest in growth associated with body weight below the lower limit of their peers $(<28$ and $<36 \mathrm{~kg}$ for $8-10$ and 11-17-year-olds, respectively). In total, 39 (69.6\%) patients were taking anti-epileptic medications.

All of the patients had some form of dysphagia, with eight (14.3\%) patients with mild, 18 (32.1\%) with moderate and 30 (53.6\%) with severe dysphagia. Reduced lip consistency and uncontrolled tongue movements hindered chewing and bolus preparation, making feeding slow. Swallowing dysfunction and upper gastrointestinal motility disorders were associated with other anomalies, including gastroesophageal reflux disease (60.7\%) and a history of recurrent bronchitis (85.7\%), aspiration (14.3\%) and $a b$ ingestis pneumonia requiring percutaneous endoscopic gastrostomy (PEG; 3.6\%). Open bite was identified in $50(89.3 \%)$ patients [Table 1].

All of the patients had Angle's class II malocclusion. Four (7.1\%) patients had $<2 \mathrm{~mm}$ malocclusion, 10 (17.9\%) had 2-3 mm malocclusion, 26 (46.4\%) had 3-4 $\mathrm{mm}$ malocclusion and $16(28.6 \%)$ had $>4 \mathrm{~mm}$ malocclusion. Overall, all patients with $<2 \mathrm{~mm}$ malocclusion and $40 \%$ of patients with $2-3 \mathrm{~mm}$ malocclusion had mild dysphagia, while $60 \%$ and $38.5 \%$ of patients with 2-3 and 3-4 mm malocclusion, respectively, had moderate dysphagia. Severe dysphagia was observed 


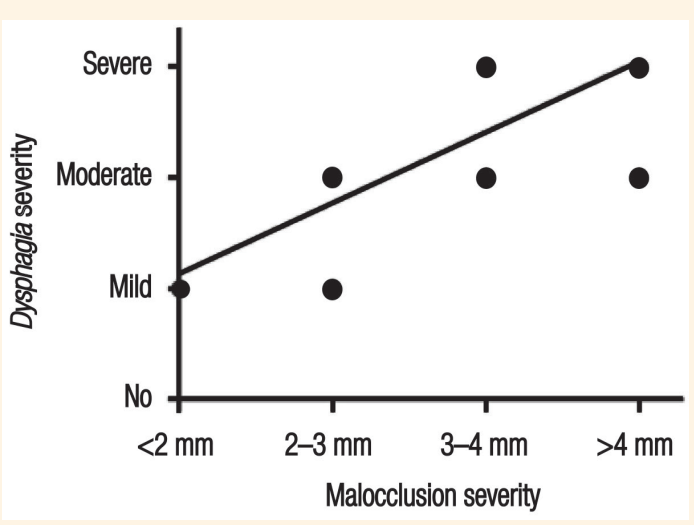

Figure 3: Chart showing a statistically significant correlation $(P<0.001)$ between dysphagia and malocclusion severity among patients with Rett syndrome admitted to the University Hospital of Siena, Siena, Italy $(\mathrm{N}=56)$.

in $28.6 \%$ and $87.5 \%$ of patients with $3-4$ and $>4 \mathrm{~mm}$ malocclusion, respectively [Table 2 and Figure 2]. According to a linear regression analysis, there was a statistically significant correlation between dysphagia and malocclusion severity $(P<0.001)$ [Figure 3].

\section{Discussion}

Swallowing is a complex biological process, with the oral preparatory and propulsive stages closely linked to events in the pharyngeal phase. ${ }^{7,13,16-18}$ The oral phase begins when the tongue pushes the bolus up and posteriorly towards the oropharynx. The propulsive action of the tongue is the result of the centripetal movement of the central groove of the tongue with the tip pressed against the hard palate and the sides of the tongue contacting the oral phase of the upper dental arch. The process lasts less than a second and involves closing the lips to prevent the bolus falling laterally. The jaw is normally kept closed by the action of the temporal, masseter, internal pterygoid and external pterygoid muscles.

Since the tongues of RS patients tend to move repetitively up and down without creating enough compression against the palate to push the bolus into the pharynx, the palate has a poor glossopharyngeal seal resulting in the escape of liquids from the mouth into the pharynx (i.e. pharyngeal spillover and the premature fall of bolus). An incorrect tongue position and irregular tongue movements inevitably aggravate maxillary protrusion. Advancement of the maxilla makes it difficult to move the tongue towards the oropharynx, resulting in the lateral leakage of food. This condition is often aggravated by lip incontinence due to hypotonia of the orbicularis muscles.

All patients with RS have structural and functional abnormalities that impair the oral phase, such as reduced lip continence, drooling, open-mouth breathing, involuntary tongue movements, open bite, growth defects of the maxilla, incorrect mandibular positioning and neurogenic scoliosis with double curve deformation. $^{6-9}$ Molina-García et al. found that anterior open bite, ogival palate, bruxism, open-mouth breathing and tongue thrusting were common in patients with RS. ${ }^{19}$ Fuertes-González et al. reported diurnal bruxism to be the most frequent oral habit of patients with RS, followed by stereotypical tongue movements and openmouth breathing. ${ }^{14}$ Despite a decreased incidence of caries compared to the control group, RS patients also had greater periodontal alterations and an increased prevalence of drooling, dental wear, high-arched palates and anterior open bite. ${ }^{14}$ In addition, RS patients often demonstrate digit sucking and orofacial motor functional disorders; in the early stages of the disease, these characteristics can give rise to malocclusions such as anterior open bite and a high-arched palate..$^{20}$

To the best of the authors' knowledge, this preliminary study is the first to show a significant association between malocclusionand dysphagia severityinpatients with RS. Although there are many causes of dysphagia in patients with RS, malocclusion is an obvious impediment to the oral phase of physiological swallowing. In the current study, a higher degree of malocclusion was found to be associated with more severe dysphagia, with an increase in the degree of misalignment of the maxillary and mandibular teeth corresponding to a more severe degree of dysphagia. Presumably, correcting the malocclusion could potentially reduce the severity of dysphagia and promote a normal diet, delaying the risk of ab ingestis pneumonia and PEG, thus improving the patient's quality of life.

Unfortunately, initiating such corrective measures for patients with RS is complex and often logistically difficult due to postural requirements and lack of patient cooperation during radiological procedures. Should future techniques allow X-rays to be taken in different positions, it might be possible to undertake appropriate interventions to correct malocclusion and tongue position in patients with RS. However, it is important to reiterate that malocclusion is only one possible cause of dysphagia in RS; therefore, the correction of malocclusion alone may not completely eliminate dysphagia in RS patients. It is therefore recommended that further research be undertaken to evaluate malocclusion in a larger sample of RS patients.

\section{Conclusion}

This preliminary study showed a significant correlation between malocclusion and dysphagia in patients with RS, with a higher degree of malocclusion associated with 
more severe dysphagia. Based on these findings, it can be postulated that correction of the malocclusion would result in improvements in the oral preparatory phase of swallowing and, therefore, in dysphagia severity. This would promote a normal diet, delaying the risk of $a b$ ingestis pneumonia, ultimately improving the patient's quality of life. However, it is important to note that malocclusion is only one possible cause of dysphagia in RS and therefore such corrective measures may prove insufficient to treat affected patients.

\section{CONFLICT OF INTEREST}

The authors declare no conflicts of interest.

\section{FUNDING}

No funding was received for this study.

\section{References}

1. Moser SJ, Weber P, Lütschg J. Rett syndrome: Clinical and electrophysiologic aspects. Pediatr Neurol 2007; 36:95-100. https://doi.org/10.1016/j.pediatrneurol.2006.10.003.

2. Laurvick CL, de Klerk N, Bower C, Christodoulou J, Ravine D, Ellaway $\mathrm{C}$, et al. Rett syndrome in Australia: A review of the epidemiology. J Pediatr 2006; 148:347-52. https://doi.org/10. 1016/j.jpeds.2005.10.037

3. Rett A. [On a unusual brain atrophy syndrome in hyperammonemia in childhood]. Wien Med Wochenschr 1966; 116:723-6.

4. Ip JPK, Mellios N, Sur M. Rett syndrome: Insights into genetic, molecular and circuit mechanisms. Nat Rev Neurosci 2018; 19:368-82. https://doi.org/10.1038/s41583-018-0006-3.

5. Neul JL, Kaufmann WE, Glaze DG, Christodoulou J, Clarke AJ, Bahi-Buisson N, et al. Rett syndrome: Revised diagnostic criteria and nomenclature. Ann Neurol 2010; 68:944-50. https://doi.org/ 10.1002/ana.22124.

6. Hagberg B. Clinical manifestations and stages of Rett syndrome. Ment Retard Dev Disabil Res Rev 2002; 8:61-5. https://doi.org/ 10.1002/mrdd.10020.

7. Mezzedimi C, Livi W, De Felice C, Cocca S. Dysphagia in Rett syndrome: A descriptive study. Ann Otol Rhinol Laryngol 2017; 126:640-5. https://doi.org/10.1177/0003489417723033.
8. Viviano M, Hayek J, Lorenzini G, Viviano F, Vinci D, Batoni L, et al. Odontosomatologic anomalies associated with Rett syndrome in 216 patients. Int J Clin Dent 2012; 5:357-61.

9. Peak J, Eveson JW, Scully C. Oral manifestation of Rett's syndrome. Br Dent J 1992; 172:248-9. https://doi.org/10.1038/sj.bd j.4807837.

10. Hennessy MJ, Haas RH. The orthopedic management of Rett syndrome. J Child Neurol 1988; 3:S43-7. https://doi.org/10.117 7/0883073888003001S09.

11. Lotan M, Merrick J, Carmeli E. Managing scoliosis in a young child with Rett syndrome: A case study. ScientificWorldJournal 2005; 5:264-73. https://doi.org/10.1100/tsw.2005.33.

12. Reilly S, Cass H. Growth and nutrition in Rett syndrome. Disabil Rehabil 2001; 23:118-28. https://doi.org/10.1080/0963 8280150504199 .

13. Schindler O, Ruoppolo G, Schindler A. [Swallowing], 2nd ed. Torino, Italy: Omega Edizioni, 2011. Pp. 349-75.

14. Fuertes-González MC, Silvestre FJ. Oral health in a group of patients with Rett syndrome in the regions of Valencia and Murcia (Spain): A case-control study. Med Oral Patol Oral Circ Bucal 2014; 19:e598-604. https://doi.org/10.4317/medor al.19743.

15. Angle EH. Treatment of Malocclusion of the Teeth and Fractures of the Maxillae: Angle's system, 6th ed. Philadelphia, Pennsylvania, USA: Andesite Press, 1900. Pp. 248-56.

16. Baikie G, Ravikumara M, Downs J, Naseem N, Wong K, Percy A, et al. Gastrointestinal dysmotility in Rett syndrome. J Pediatr Gastroenterol Nutr 2014; 58:237-44. https://doi.org/10.1097/ MPG.0000000000000200.

17. Lotan M, Zysman L. The digestive system and nutritional considerations for individuals with Rett syndrome. ScientificWorldJournal 2006; 6:1737-49. https://doi.org/10.1100/tsw.2006.264.

18. AlDallal SM, AlKathemi MM, Haj WH, AlDallal NM. Dental health in sickle cell disease. J Med Ther 2017; 1:1-4. https://doi. org/10.15761/JMT.1000105.

19. Molina-García A, Castellanos-Cosano L, Machuca-Portillo G, Posada-de la Paz M. Impact of rare diseases in oral health. Med Oral Patol Oral Circ Bucal 2016; 21:e587-94. https://doi. org/10.4317/medoral.20972.

20. Fuertes-González MC, Silvestre FJ, Almerich-Silla JM. Oral findings in Rett syndrome: A systematic review of the dental literature. Med Oral Patol Oral Circ Bucal 2011; 16:e37-41. https://doi.org/10.4317/medoral.16.e37. 